\title{
Prevalência de anticorpos contra Babesia bovis (Babés, 1888) e B. bigemina (Smith e Kilborne, 1893) (Apicomplexa: Babesiidae) em bovinos de quatro municípios do Estado do Rio de Janeiro
}

\section{Prevalence of antibodies against Babesia bovis (Babés, 1888) and $B$. bigemina (Smith \& Kilborne, 1893) (Apicomplexa: Babesiidae) in cattle from four municipality of Rio de Janeiro State}

\author{
Cláudio Roberto Madruga, ${ }^{*}$ Marcos Moreira Braga, ${ }^{\star \star}$ Denise Botelho de Oliveira, ${ }^{\star \star \star}$ Carlos Luiz Massard, ${ }^{\star \star \star \star}$ \\ Cleber Oliveira Soares ${ }^{\star \star \star \star \star}$
}

\begin{abstract}
Resumo
Realizou-se um levantamento sorológico para o diagnóstico de anticorpos da classe lgG contra $B$. bovis e B. bigemina utilizando-se o teste de imunofluorescência indireta (IFI). No total examinou-se 218 soros colhidos em quatro municípios de diferentes regiões do Estado do Rio de Janeiro. A soroprevalência encontrada foi de $82,11 \%$ para $B$. bovis e $94,03 \%$ para $B$. bigemina. Oitenta e três soros foram examinados comparativamente nos testes de $|F|$ e teste de conglutinação rápida em placa (TCR). Os resultados, soropositivos, foram $87,95 \%$ e $92,77 \%$ na IFI e $85,54 \%$ e $98,79 \%$ no TCR, respectivamente, para B. bovis e B. bigemina. Estes dados indicam que os municípios estudados são áreas de estabilidade enzoótica. A análise de variância indicou que o TCR tem sensibilidade idêntica a da IFI, não diferindo significativamente $\left(P^{3} 0,05\right)$, tanto no diagnóstico de anticorpos contra B. bovis, como contra B. bigemina. Estes dados indicam que o TCR é uma técnica viável para estudos soroepidemiológicos.
\end{abstract}

Palavras-chave: Babesia bovis; Babesia bigemina; babesiose; epidemiologia; imunofluorescência indireta; teste de conglutinação rápida.

\begin{abstract}
A serological survey was conducted to determine the isotype $\lg G$ antibodies prevalence against $B$. bovis and $B$. bigemina. Two thousands and eighteen sera from four municipality of Rio de Janeiro were collected and analysed by the indirect fluorescent antibodies technique (IFAT). Overall $82.11 \%$ and $94.03 \%$ were positive. Eighty three sera were comparatively analized in IFAT and rapid conglutination test (RCT). A total of $87.95 \%$ and $92.77 \%$ of animals were found to be positive, respectively, to $B$. bovis and B. bigemina in the IFAT, while $85.54 \%$ and $98.79 \%$ showed seroconversion to former and latter specie of Babesia in the RCT. These results suggest that infection with both Babesia species is widespread throughout the region characterizing an enzootically stable situation. Both tests showed identical sensitivity $\left(P^{3} 0,05\right)$ to detect antibodies against $B$. bovis and $B$. bigemina. These data indicate that RCT is suitable to epidemiological studies.
\end{abstract}

Keywords: Babesia bovis; Babesia bigemina; babesiosis; epidemiology; indirect immunofluorescent antibodies technique; rapid conglutination test.

\section{Introdução}

A babesiose bovina é causada por dois hemoprotozoários, Babesia bovis (Babés, 1888) e B. bigemina (Smith e Kilborne, 1983) e parece ocorrer desde o século passado. A primeira identificação destes babesídeos no país foi realizada em 1901, no Estado do Rio de Janeiro, em bovinos importados (Fajardo, 1901).
A situação epidemiológica é indicativa da possibilidade da ocorrência ou não de surtos de babesiose. A dinâmica da infecção por Babesia spp. é dependente de vários fatores: da população infestante de carrapato e de sua capacidade de transmissão que é determinada pela taxa de inoculação (Mahoney, 1975, Madruga et al., 1984); pela susceptibilidade dos bovinos, que pode variar com a raça (Francis, 1966), idade (Pipano, 1969), estado fisiológico e estado imunitário (Mahoney et al., 1977).

\footnotetext{
* Pesq. da EMBRAPA - Centro Nacional de Pesquisa de Gado de Corte. Campo Grande - MS. Caixa

** Prof. Titular do Dep. de Patologia e Clínica Veterinária, Faculdade de Veterinária, UFF, Niterói, RJ.

*** Profa. Adjunto do Dep. de Patologia e Clínica Veterinária, Faculdade de Veterinária, UFF, Niterói, RJ.

**** Prof. Titular do Dep. de Parasitologia Animal, Instituto de Biologia, UFRRJ, Seropédica, RJ.

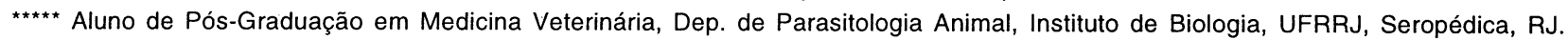


Considerando que a distribuição das babésias, parasitas dos bovinos, está associada à presença do carrapato Boophilus microplus e que a prevalência é elevada em algumas regiões do país (Alves, 1987 ; Patarroyo et al., 1987 ; Linhares, 1991), é estimado que aproximadamente 130 milhões de bovinos estão sujeitos a infecção por $B$. bovis e $B$. bigemina e que a maioria do território brasileiro está sob condições de estabilidade enzoótica. Isto ocorre quando os bezerros se infectam nos primeiros meses de vida, pois nesta faixa etária são menos susceptíveis a desenvolverem a babesiose (Latif et al., 1979). Após a infecção primária os bovinos estabelecem uma potente imunidade contra reinfecções.

Além das áreas situadas abaixo do paralelo $32^{\circ} 30^{\prime}$ latitude Sul (Leite et al., 1989), apenas algumas áreas restritas situadas em grandes altitudes e que são atingidas por inverno rigoroso e regiões do agreste nordestino apresentam, potencialmente, condições para instabilidade enzoótica. Apesar disto, casos de babesiose não se restringem a estas áreas. Em regiões enzoóticas de São Paulo (Valente e Amaral, 1971), Minas Gerais (Patarroyo et al., 1987) e no Mato Grosso do Sul (Madruga et al., 1984) as infecções por B. bovis e B. bigemina são consideradas como importantes causas de doenças em bezerros.

Dados do Ministério da Agricultura comprovam que a babesiose ocorre com alta freqüência. Uma estimativa realizada no ano de 1983 revela que, naquele ano, foi gasto 1,5 milhão de dólares em babesícidas (Brasil, 1985). Portanto, é importante determinar a prevalência da infecção de organismos do gênero Babesia em bovinos com idade superior a oito meses para orientar medidas preventivas contra esta enfermidade.

\section{Materiais e métodos}

\section{Amostras de soros}

A amostragem foi realizada em quatro municípios do Estado do Rio de Janeiro: Barra Mansa $(n=54)$, Itaguaí $(n=55)$, Santa Maria Madalena $(n=54)$ e Iguaba $(n=55)$, totalizando 218 amostras. O tamanho da amostragem foi determinada pela fórmula do Centro Pan-Americano de Zoonoses (1979) para estudos de enfermidades infecciosas crônicas após um levantamento preliminar com 83 soros dos quatro municípios em estudo. O sangue foi colhido assepticamente de bovinos leiteiros, sem raça definida, de ambos os sexos, com idade acima de oito meses. O soro obtido foi armazenado a $-20^{\circ} \mathrm{C}$ até o momento da análise sorológica.

\section{Imunofluorescência Indireta (IFI)}

Esta técnica foi realizada para diagnóstico de anticorpos contra $B$. bovis e $B$. bigemina de acordo com a técnica descrita anteriormente (Madruga et al., 1986) utilizando isolados do Estado de Mato Grosso do Sul (Kessler et al., 1987) para a preparação de antígeno. Resumidamente, o antígeno de $B$. bovis foi preparado com sangue de bezerro com parasitemia de $5,2 \%$, colhido cinco dias pós-inoculação, antes da formação de anticorpos contra este hemoparasito. $O$ antígeno de $B$. bigemina foi obtido de um bezerro com parasitemia de $10,5 \%$, colhido com critérios idênticos aos descritos acima.
Nas lâminas contendo antígeno após a secagem foram feitos círculos com esmalte opaco nos quais foram colocados $10 \mathrm{ml}$ de soros testes e controles (positivo e negativo) para posterior incubação em câmara úmida, a $37^{\circ} \mathrm{C}$, durante trinta minutos. Após este período, as lâminas foram lavadas três vezes por períodos de dez minutos, em tampão salino fosfatado $\mathrm{pH} 7,2$, sob agitação constante. No interior de cada círculo foram colocados $10 \mu \mathrm{l}$ de conjugado, IgG de coelho antiimunoglobulina $G$ bovina, marcada com isotiocianato de fluoresceína e incubado por 30 minutos em câmara úmida. Após duas lavagens com o mesmo tampão mencionado, durante dez minutos, uma lavagem adicional foi feita com água destilada por cinco minutos.

As lâminas foram examinadas em microscópio com lâmpada de mercúrio (HBO-100), utilizando um filtro de barreira com $480 \mathrm{~nm}$ e objetiva de $50 \mathrm{X}$. Os soros foram considerados positivos quando foi observada fluorescência na diluição 1:80.

\section{Teste de Conglutinação Rápida (TCR)}

A preparação dos antígenos e a execução da prova de TCR para dianóstico de anticorpos contra $B$. bigemina e $B$. bovis foram descritas anteriormente (Madruga et al., 1995). Resumidamente, a prova foi realizada colocando-se em uma placa de vidro $15 \mu \mathrm{l}$ de soro teste, $30 \mu \mathrm{l}$ de fator sérico bovino (coleção de soros de nelores clinicamente saudáveis e sorologicamente negativos para Anaplasma spp. e Babesia spp.) e $15 \mu \mathrm{l}$ de antígeno. Após a mistura dos componentes e a homogeneização constante por cinco minutos, procedeuse à leitura. Em todas as provas foram adicionados controles positivos e negativos.

A interpretação foi a seguinte: negativo (-), sem formação de grumos de aglutinação; positivo $(+)$, reação de aglutinação fraca; positivo $(++)$, reação de intensidade regular; positivo $(+++)$, reação de aglutinação forte e positivo $(++++)$, reação de aglutinação muito forte.

\section{Análise estatística}

O modelo matemático para análise de variância (ANOVA) contém os efeitos das infecções por $B$. bovis e $B$. bigemina, os testes de TCR e IFI e a interação simples entre eles. Utilizouse no modelo o grau de confiança a partir de $95,0 \%$.

\section{Resultados e discussão}

$A$ análise de 218 soros pela IFI apresentou $82,11 \%$ positivos para $B$. bovis e $94,03 \%$ para $B$. bigemina (Tabela 1 ). No exame comparativo de 83 soros por meio das técnicas de $|F|$ e TCR, a prevalência de $B$. bovis foi $87,95 \%$ na IFI e $85,54 \%$ no TCR, enquanto para $B$. bigemina foi de $92,77 \%$ e $98,79 \%$, respectivamente, na IFI e TCR (Tabela 1). Ambos resultados indicam que a infecção por estas duas espécies de Babesia ocorre enzooticamente. Isto implica que estes municípios são áreas de estabilidade enzoótica, pois prevalências entre 75 a $100 \%$ significam que a babesiose ocorre apenas de forma esporádica, pois existe uma pequena porção da população com risco de contrair a doença (Mahoney, 1975).

Estes resultados são esperados, pois na maioria das áreas comprendidas entre os paralelos $32^{\circ}$ latitude Sul e $40^{\circ}$ latitude Norte, os vetores da $B$. bovis e $B$. bigemina, carrapa- 
Tabela 1: Prevalência de anticorpos anti Babesia bovis e anti B. bigemina em bovinos, no estado do Rio de Janeiro, pelas técnicas de Imunofluorescência Indireta (IFI) e o Teste de Conglutinação Rápida (TCR).

\begin{tabular}{lcccccc}
\hline \multirow{8}{*}{ Resultado } & \multicolumn{1}{c}{ Técnica sorológica } \\
\cline { 2 - 7 } & B. bovis $(n=218)$ & B. bigemina & B. bovis & B. bigemina & B. bovis & B. bigemina \\
\hline Positivo & $82,11 \%(179)$ & $94,03 \%(205)$ & $87,95 \%(73)$ & $92,77 \%(77)$ & $85,54 \%(71)$ & $98,79 \%(82)$ \\
Negativo & $17,89 \%(39)$ & $5,97 \%(13)$ & $12,05 \%(10)$ & $7,23 \%(6)$ & $14,46 \%(12)$ & $1,21 \%(1)$ \\
\hline
\end{tabular}

Não houve diferença significativa $\left(P^{3} 0,05\right)$ entre a soroprevalência de Babesia bovis e $B$. bigemina, bem como entre os testes sorológicos.

tos do gênero Boophilus, estão amplamente difundidos (Leite et al., 1989). As prevalências de ambas espécies de Babesia nas regiões estudadas do Estado do Rio de Janeiro não diferem significativamente de outros estados do país, com exceção da prevalência de $B$. bovis no Estado de Pernambuco.

Levantamento sorológico realizado em Pernambuco determinou uma percentagem de $87,9 \%$ de imunoglobulinas anti- $B$. bigemina, enquanto que a percentagem de animais com anticorpos contra B. bovis foi de apenas $27,8 \%$ (Alves, 1987), taxa consideravelmente abaixo do nível mínimo de estabilidade enzoótica. Na Zona da Mata no Estado de Minas Gerais a percentagem de bovinos positivos na prova de IFI foi estimada em $79,0 \%$ e $82,5 \%$, respectivamente, para $B$. bigemina e $B$. bovis (Patarroyo et al., 1987). No Estado de Goiás também foi encontrada prevalências elevadas para ambas espécies de Babesia, $97,5 \%$ de soropositivos anti-B. bigemina e $98,7 \%$ anti$B$. bovis (Linhares, 1991). Estes dados estão plenamente de acordo com outro Estado do Centro-Oeste do Brasil, Mato Grosso do Sul, onde foi constatado que as taxas de transmissão de ambas espécies de Babesia são elevadas e que todos os

\section{Referências bibliográficas}

ALVES, L. C. Prevalência da babesiose em gado leiteiro no município de Garanhuns, Estado de Pernambuco. 1987. 124 p. Tese (Mestrado) - Faculdade de Medicina Veterinária e Zootecnia da Universidade de São Paulo.

APPLEWHAITE, L. M., CRAIG, T. M., WAGNER, G. G. Serological prevalence of bovine babesiosis in Guyana. Trop An Hith Prod, v. 13, p. 13-18. 1981.

BRASIL. Ministerio da Agricultura e Reforma Agrária. Secretaria de Defesa Sanitária Animal. Carrapato, berne e bicheira no Brasil. Brasília, D.F. 1985. 153 p.

CENTRO PAN-AMERICANO DE ZOONOSES Procedimientos para estudios de prevalencia por muestreo. Buenos Aires : Ramos Mejia, 1979. 35 p. (Nota Técnica 18. Rev.1).

FAJARDO, F. A. Piroplasmose bovina no Rio de Janeiro. Rev Med, v. 14, p. 18-30, 1901.

FRANCIS, J. Resistance of zebu and other cattle to tick infestation and babesiosis with special reference to Australia: An historical review. Brit Vet J, v. 122, p. 301-307, 1966.

KESSLER, R. H., MADRUGA, C. R., DE JESUS, E. F. et al. Isolamento de cepas puras de Babesia bovis, Babesia bigemina e Anaplasma bezerros se infectam, com $B$. bovis e $B$. bigemina, antes dos oito meses de idade (Madruga et al., 1984).

A maior prevalência de $B$. bigemina $(P \geq 0,001)$ está de acordo com a maioria dos estudos realizados em diversas partes do mundo, onde o $B$. microplus é o vetor destas babésias (Applewhaite et al., 1981). Este fenômeno é pertinente, pois a $B$. bigemina é transmitida ao bovino de forma mais eficiente que a $B$. bovis, por este ixodídeo (Mahoney et al., 1973).

Os resultados da subamos-tragem não evidenciaram diferenças significativas $(P \geq 0,05)$ entre $I F I$ e TCR no diagnóstico de anticorpos contra $B$. bovis e contra $B$. bigemina, comprovando que a sensibilidade dos dois testes são semelhantes. Estes resultados colocam o TCR com uma sensibilidade comparável ao teste da imunoadsorção enzimática (ELISA), prova considerada como de maior sensibilidade no diagnóstico de anticorpos contra organismos do gênero Babesia (Waltsbuhl et al., 1989).

\section{Conclusões}

Este primeiro estudo epidemiológico no Estado do Rio de Janeiro envolvendo quatro municípios mostra que as infecções por organismos do gênero Babesia ocorrem endemicamente. O TCR apresentou desempenho similar a IFI, portanto, pode ser aplicado em estudos epidemiológicos neste estado. Devido à sua simplicidade de execução, a utilização desta prova poderá ampliar o conhecimento epidemiológico da babesiose bovina não somente nas diversas microrregiões do Estado do Rio de Janeiro, como também em outras áreas do Brasil.

marginaleem área enzoótica. Pesq Agrop Bras, v. 22, p. 747-752, 1987.

LATIF, B. M. A., SAID, M. S., ALI, S. R. Effect of age on the immune response of cattle experimentally infected with $B$. bigemina. Vet Parasitol, n. 5, p. 307-312, 1979.

LEITE, A. M. O., ARNONI, J., SILVA, S. S., et al. Serological study of bovine babesiosis in a marginal area of Brasil. NATIONAL VETERINARY HEMOPARASITEDISEASECONFERENCE8., St. Louis. Proceedings. St. Louis. Veterinary Hemoparasitic Disease Research Workers, p. 624-635, 1989. .

LINHARES, G. F. C. Estudo soroepidemiológico de B. bigemina (Smith e Kilborne, 1983) e B. bovis (Babés, 1888) em bovinos no município de Goiania, GO, Brasil (Protozoa: Babesiidae).1991. 94 p. Tese (Mestrado) - Instituto de Biologia da Universidade Federal Rural do Rio de Janeiro.

MADRUGA, C. R., GOMES, R. F., SCHENK, M. A. M. et al. Etiologia de algumas doenças de bezerros de corte no Estado de Mato Grosso do Sul. Campo Grande : EMBRAPA-CNPGC. 27 p. (EMBRAPACNPGC. Circular Técnica, 15). 1984.

KESSLER, R. H., JESUS, E. F., et al. Imunofluorescência indireta para diagnóstico sorológico de Babesia bigemina e Babesia bovis. Produção de antígenos com cepas isoladas no Estado de 
Mato Grosso do Sul e avaliação preliminar do teste. Campo Grande: EMBRAPA-CNPGC, 6p. (EMBRAPA-CNPGC. Pesquisa em Andamento, 32.), 1986.

KESSLER, R. H., SCHENK, M. A. M. et al. Análise do desempenho dos testes de conglutinação rápida para diagnóstico de anticorpos contra Babesia bovis e Babesia bigemina. Arq Bras Med Vet Zoot, v. 47 n. 5, p. 649-657, 1995.

MAHONEY, D. F., WRIGHT, I. G., MIRRE, G. B. Bovine babesiosis: the persistence of immunity to Babesia argentina and Babesia bigemina in calves (Bos taurus) after naturally acquired infection. Ann Trop Med Parasitol, v. 67, p. 197-201, 1973.

The diagnosis of babesiosis in Australia. In Workshop on Hemoparasites (Anaplasmosis and Babesiosis). Cali, Colombia. Wells E. A., p. 49-62, 1975.

KERR, J. D., GOODGER, B. V. et al. The immune response of cattle to Babesia bovis (syn $B$. argentina). Studies on the nature and specificity of protection. Intern J Parasitol, v. 9, p. 297-306, 1977.

PATARROYO, J. H., RIBEIRO, M. F. B., SANTOS, J. L. Epidemiologia das babesioses bovinas no Estado de Minas Gerais I. Prevalência de anticorpos fluorescente na "Zona da Mata" MG. Arq Bras Med Vet Zoot, v. 39, p. 423-429, 1987.

PIPANO, E. Immunization of cattle against Babesiella berbera infection. I. Infection of cattle with blood from patent and latent carriers. Refuah Vet, v. 29, p. 11-15, 1969.

VALENTE, F. A. T., AMARAL, L. B. Ocorrência de moléstia nos rebanhos bovinos do Estado de São Paulo no triênio 1965/67. V. Piroplasmose e anaplasmose na região de São Paulo, Sorocaba e Bauru, SP. O Biológico, v. 37, p. 84-90, 1971.

WALTISBUHL, D. J., GOODGER, B. V., WRIGHT, J. G. et al. An enzyme linked immunosorbent assay to diagnosis. Babesia bovisinfection in cattle. Parasitol Res, v. 73, p. 126-131, 1987. 